\title{
Design and Synthesis of a New Amphipathic Cyclic Decapeptide with Rapid, Stable, and Continuous Antibacterial Effects
}

\author{
Hisham N. Farrag, Khaled Metwally, Shinya Ikeno and Tamaki Kato* \\ Department of Biological Functions Engineering, Graduate School of Life Science and Systems Engineering. \\ Kyushu Institute of Technology, Wakamatsu Campus, Fukuoka Prefecture, 808-0196 Japan
}

\begin{abstract}
Pathogens can acquire high resistance against even the most powerful antibiotics because of the long periods of treatment and high usage of antimicrobial agents. In addition, the severe side effects of commonly used antibiotics can initiate secondary diseases or may lead to death. Antimicrobial peptides (AMPs) have been reported to exhibit prokaryotic selectivity and low microbial resistance. Furthermore, AMPs show a good ability to penetrate the cell walls of microorganisms. In this study, a cyclic decapeptide and its linear counterpart were synthesized by a standard solid phase peptide synthesis method (SPPS) in a quantitative yield of the linear decapeptide (97\%) and a good yield of the cyclic form (45\%). Antibacterial studies were performed using Escherichia coli (a widespread Gram-negative pathogen) and Bacillus thuringiensis as a representative Gram-positive pathogen. The minimal inhibitory concentration (MIC) values were evaluated by the broth microdilution method. The cyclic peptide and its linear counterpart exhibited MIC values of 0.16 and 0.3 $\mathrm{mg} / \mathrm{mL}$, respectively, against Escherichia coli. Against Bacillus thuringiensis, the peptides had the same MIC value of $0.24 \mathrm{mg} / \mathrm{mL}$. Time-kill studies were performed using E. coli, which indicated a fast killing effect of both peptides ( $\geq 99 \%$ of the bacterial cells) after $1 \mathrm{~h}$ of incubation using a concentration of two times the MIC value for each peptide.

ARTICLE INFO

Article history:

Received: 10 February 2020

Accepted: 13 November 2020

Published: 31 December 2020

DOI: https://doi.org/10.47836/pjst.28.S2.15

$\overline{\text { E-mail addresses: }}$

farrag.hisham320@mail.kyutech.jp (Hisham N. Farrag)

metwally.khaled-abdelfatteh735@mail.kyutech.jp (Khaled Metwally)

ikeno@life.kyutech.ac.jp (Shinya Ikeno) Moreover, bacterial cell viability studies against $E$. coli carried out using a high bacterial concentration showed that both peptides have a maximum killing effect of more than $80 \%$ of the tested bacterial cells.

Keywords: Antibiotics, antimicrobial peptides, cyclic decapeptides, Escherichia coli, SPPS
\end{abstract}

tmkato@life.kyutech.ac.jp (Tamaki Kato)

* Corresponding author 


\section{INTRODUCTION}

Antimicrobial agents can act as double-edged swords, as they can affect the targeted microorganisms but also have harmful effects on the host cells (Brummett \& Fox, 1989; Khaliq \& Zhanel, 2003; Mingeot-Leclercq \& Tulkens, 1999). The most effective antimicrobial agents exhibit high selectivity toward a microorganism's cells without affecting the mammalian cells. In addition, the microorganisms should show no resistance toward the antimicrobial agent during the treatment. Recently, antimicrobial peptides (AMPs) produced by some types of fungi have been reported to have rapid and strong effects on microorganisms via destruction of the cell membranes (Stengel et al., 2001). The degradation end products of such peptides are amino acids, which indicates their potential safety. Thus, many researchers have investigated this type of peptide antibiotic, especially the natural antimicrobial decapeptides, for example, streptocidins and tyrocidins. There are two types of natural peptides, cyclic and linear peptides. Some examples of cyclic AMPs include the streptocidins (Gebhardt et al., 2001), the tyrocidins (Chalovich \& Eisenberg, 2013), gramicidin S (Swierstra et al., 2016), and the loloatins (Gerard et al., 1999). Examples of linear AMPs include the gramicidins A, B, and C (Kessler et al., 2004). The overall charge of the bacterial cell membrane plays an important role in the biological efficacy. It has been shown that most bacterial cell membranes carry negative charges because of the presence of lipoteichoic acid moieties linked to either peptidoglycan or the plasma membrane. The lipoteichoic acid moieties are negatively charged because of the presence of phosphate ions in their chemical structure (Silhavy et al., 2010). Therefore, bacterial cell walls prefer adhesion to positively charged surfaces rather than negatively charged surfaces. In addition, it has been found that there is no bacterial growth after the adhesion to positively charged surfaces (Gottenbos et al., 2001).

The hydrophobic residues of peptides are important for the penetration of AMPs into the bacterial cell wall. These hydrophobic residues can construct a nonlamellar phase via a self-assembly process inside the lipid bilayer of the bacterial cell wall (Chen et al., 2010). In addition, alanine, valine, and leucine have been investigated for their importance as aliphatic amino acids, to facilitate the formation of secondary structures in the bacterial cell membrane and to increase the solubility of peptides (Narayanan \& Dias, 2013).

Herein, a new anti-bacterial cyclic decapeptide and its linear counterpart were designed and investigated in terms of antibacterial behavior against standard and high concentrations of bacteria. Positively charged moieties incorporated in peptides encourage adherence with the negatively charged bacterial cell wall. For that purpose, four lysine amino acid residues were incorporated into the decapeptides to serve as the source of a positive charge. In addition, increasing the hydrophobicity of the whole molecule was achieved by incorporating leucine, valine, tryptophan, tyrosine, and phenylalanine into the decapeptide structure to increase the penetration of the whole peptide inside the bacterial cell membrane. The antibacterial effect was studied against the Gram-positive Bacillus 
thuringiensis and Gram-negative bacterial strain Escherichia coli. The minimal inhibitory concentration (MIC) values were determined. Time-kill studies were conducted for both forms of decapeptides against $E$. coli. Cell viability assays were performed using a high concentration of $E$. coli to study the ability of the antibacterial peptides to overcome and control a source of infection by investigating the maximum killing effect of their secondary structures.

\section{MATERIALS AND METHODS}

\section{Synthetic Protocol}

As shown in Figure 1, the linear decapeptide H-KVYKFKWLKA-OH (peptide 1) was designed to contain cationic residues (four lysine residues) to interact with the negatively charged bacterial membrane. Hydrophobic residues were added to the structure (tyrosine, tryptophan, and phenylalanine) to interact with the membrane lipids. In addition, aliphatic residues were incorporated to improve the interaction with the bacterial membrane receptors and to increase the solubility of the peptide. The cyclic decapeptide KVYKFKWLKA (peptide 2) was synthesized to study the difference in the antibacterial effect of the rigid cyclic structure compared with the linear peptide. Peptide 1 [molecular weight (MW) 1310] was prepared via the standard solid phase peptide synthesis method using 9-fluorenylmethoxycarbonyl (Fmoc) chemistry (as shown in Scheme 1) and 2-chlorotrityl

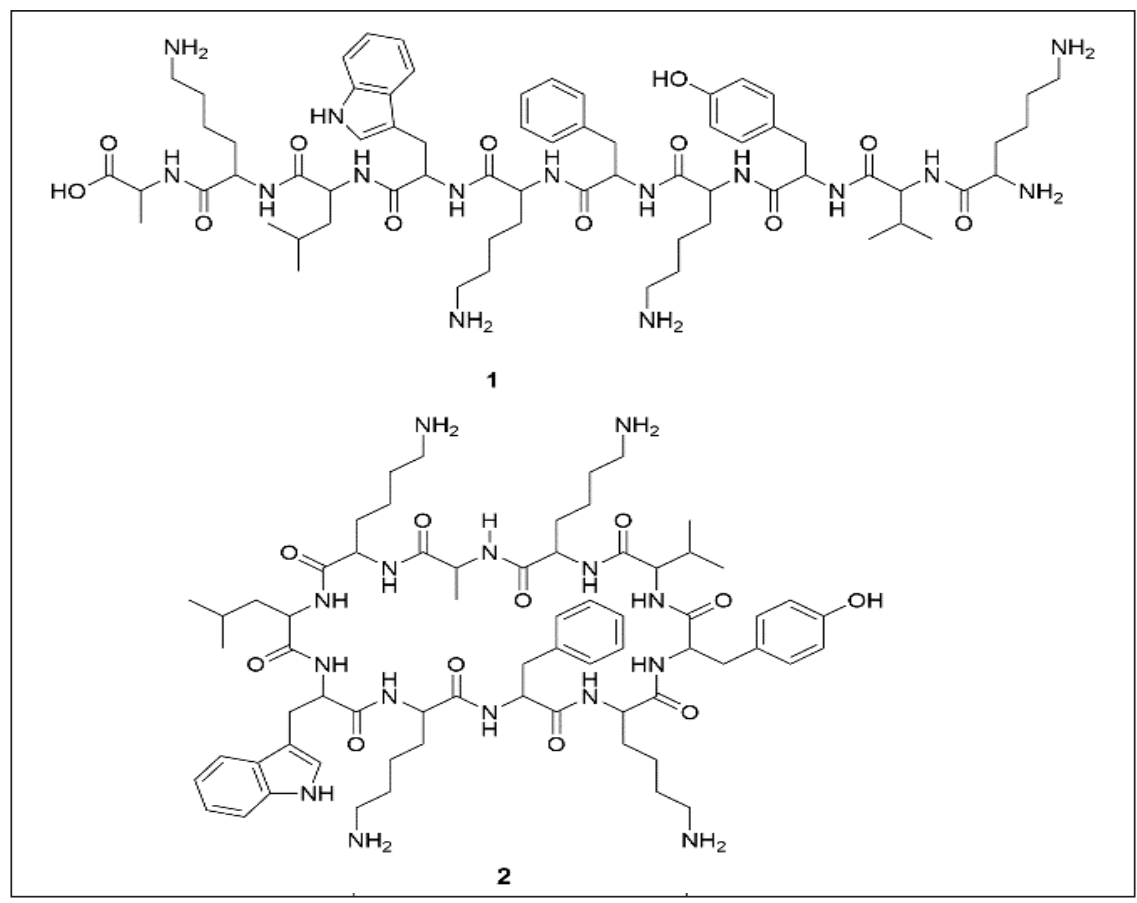

Figure 1. Design of the linear (1) and cyclic (2) antimicrobial decapeptides (KVYKFKWLKA) 
resin as the solid support (Kreutzer et al., 2018). All Fmoc-protected amino acids, resin, piperidine, $O$-benzotriazole- $N, N, N^{\prime}, N^{\prime}$-tetramethyl-uronium-hexafluorophosphate (HBTU), 1-hydroxy-benzotriazole hydrate $\left(\mathrm{HOBt} \cdot \mathrm{H}_{2} \mathrm{O}\right), N, N$-diisopropylethylamine (DIPEA), and 2, 2, 2-trifluoroacetic acid (TFA) were purchased from Watanabe Chemical Industries, Ltd, Japan. Other reagents and solvents were purchased from Wako Pure Chemical Industries, Ltd, Japan.

As shown in Scheme 1, the synthesis was started by loading an alanine amino acid onto 2-chlorotrityl chloride resin. Fmoc-L-amino acid residues were then coupled to the loaded alanine residue using HBTU, DIEA, and HOBT in $N, N$-dimethylformamide (DMF) as the solvent for the coupling process. The Fmoc protecting groups were removed using 20\% (v/v) piperidine in DMF. The cleavage of the side-chain protected linear decapeptide from the resin was performed using a mixture of 2, 2, 2-trifluoroethanol/ acetic acid/dichloromethane at a ratio of 3:1:1 (v/v/v) (Amblard et al., 2006). Purification was performed using a semi-preparative RP-HPLC Hitachi L-7100 instrument equipped with an XTerra Prep MS C18 OBD $10 \mu \mathrm{m}$ column $(19 \times 150 \mathrm{~mm}$; Waters). The mobile phases were acetonitrile containing $0.1 \%$ TFA, and $\mathrm{H}_{2} \mathrm{O}$ containing $0.1 \%$ TFA, and the peak intensity was determined at a wavelength of $220 \mathrm{~nm}$ (Huber \& Majors, 2007).

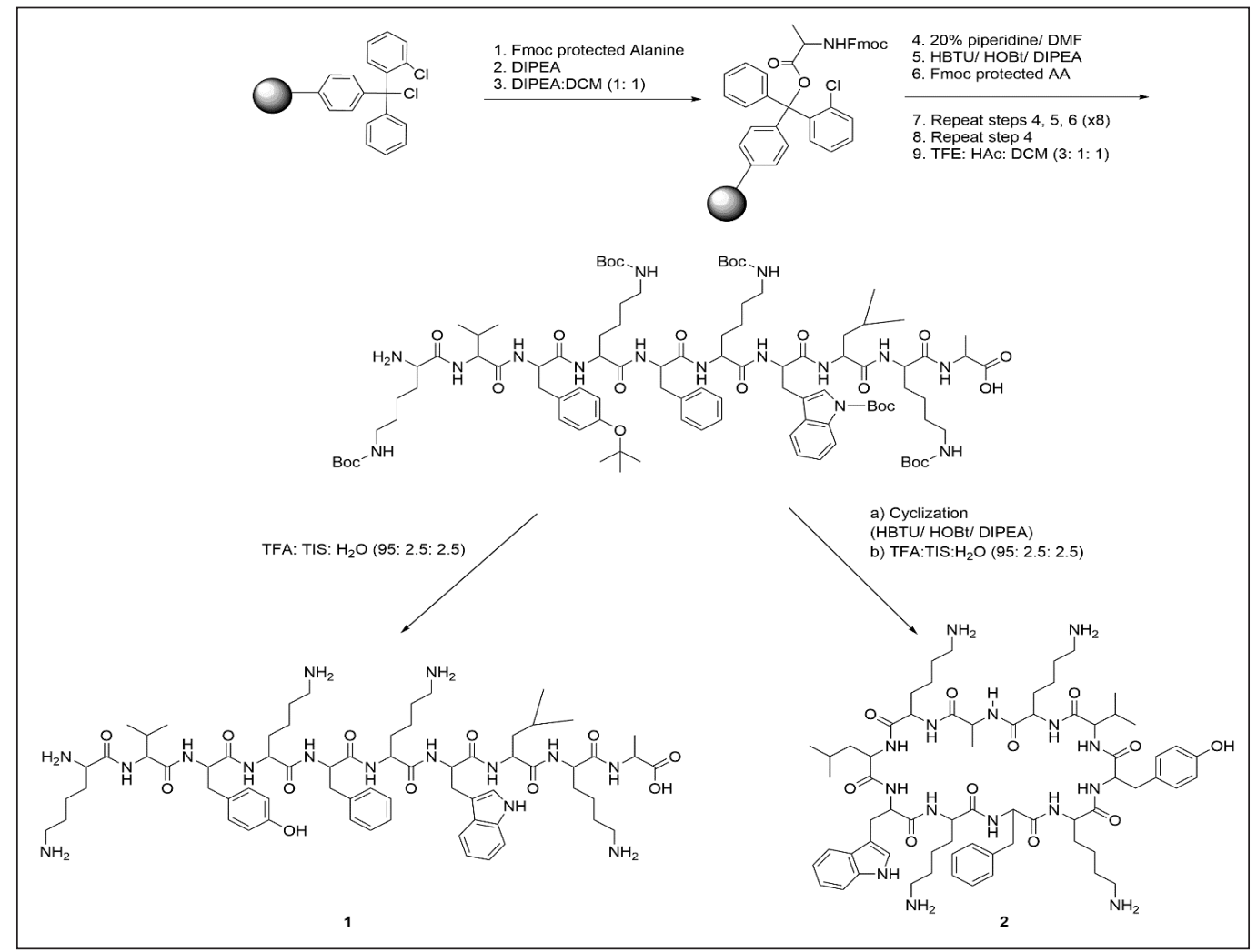

Scheme 1. Synthetic protocol of the linear and cyclic decapeptides (KVYKFKWLKA) 
The removal of the side-chain protecting groups was achieved using a mixture of TFA/ trisisopropylsilane (TIS) $/ \mathrm{H}_{2} \mathrm{O}$ at a ratio of 95:2.5:2.5 (v/v/v). Lyophilization was carried out in a VD-800F freeze dryer (TAITEC) to obtain the linear decapeptide 1 . The cyclization reaction was achieved using a concentration of $0.5 \mathrm{mM}$ of the linear decapeptide 1 to avoid dimer formation. Two equivalents (equiv.) of HBTU and 5 equiv. of DIPEA were used for the cyclization process. The removal of the protecting groups of the cyclic decapeptide was carried out using TFA/TIS $/ \mathrm{H}_{2} \mathrm{O}$ at a ratio of 95:2.5:2.5 (v/v/v). Purification was achieved using semi-preparative RP-HPLC followed by Lyophilization to yield the target cyclic decapeptide 2 (Tapeinou et al., 2015).

\section{Antibacterial Assays}

MIC Evaluation. MIC values were determined by the broth microdilution method using 96-well microplates (Standards \& Testing, 2018). E. coli and B. Thuringiensis bacterial strains were chosen to determine the broad-spectrum effect of the cyclic decapeptide and the linear counterpart against both Gram-positive and Gram-negative bacterial strains. The bacterial strains were inoculated in a freshly prepared Luria Bertani (LB) broth medium at a temperature of $37^{\circ} \mathrm{C}$ (for E.coli), and in a freshly prepared tryptic soy broth at a temperature of $27^{\circ} \mathrm{C}$ (B. thuringiensis). Both bacterial strains were shaken at $160 \mathrm{rpm}$ overnight. The cultures were diluted up to $5 \times 10^{5} \mathrm{CFU} / \mathrm{mL}\left(\mathrm{OD}_{600}=0.05\right)$. The cyclic and linear decapeptide solutions were prepared by dissolving each peptide separately in distilled water at a concentration of $1 \mathrm{mg} / \mathrm{mL}$. The stock solutions were diluted across 96-well microplates by 2 -fold serial dilution using the growth media to reach a total volume of 200 $\mu \mathrm{L}$. Negative controls were used to ensure the adequate growth of the bacteria. Kanamycin and ampicillin, 0.25 and $0.5 \mathrm{mg} / \mathrm{mL}$ solutions, respectively, were used as positive controls. The bacterial cultures were inoculated with the test and control compounds and incubated for $24 \mathrm{~h}$ at the designated temperatures for each bacteria. MIC values were determined as the minimal concentration where no visible bacterial growth was detected. All experiments were carried out in triplicate.

Time-kill Assays. Time-kill assays were performed using E. coli and 96-well microplates with clear bottoms (Nunclon ${ }^{\mathrm{TM}}$ Surface, Denmark). The bacterial culture was prepared as previously described. The killing effect was measured via a colorimetric assay using dimethyl sulfoxide (DMSO), and water-soluble tetrazolium salt (WST-8) reagent (Microbial Viability Assay Kit-WST, Dojindo, Japan). The Kit-WST can detect viable bacterial cells by a colorimetric assay. DMSO acts as an electron carrier, it carries electrons from the viable cells to WST causing a change in color from yellow to orange because of the formation of WST-8 formazan. The color change can be detected by a microplate reader at a wavelength of $460 \mathrm{~nm}$. A blank was made by the media, tested peptide, and the Kit-WST. Peptides 
1 and 2 were tested at two times the MIC values. Runs without the antimicrobial agents were performed to confirm the adequate growth of the bacteria (negative controls). The bacterial culture was added to the tested peptides and incubated in a shaking incubator at $37^{\circ} \mathrm{C}$ for $24 \mathrm{~h}$. The absorbance values were measured using a microplate reader (Perkin Elmer, USA) at $460 \mathrm{~nm}$ at different time intervals, 1,6 , and $24 \mathrm{~h}$, to determine the surviving bacterial cells. The readings were subtracted from the reagent blank and compared with the negative control to determine the \%viability. From the \%viability data, the \%killing can be determined for the tested peptides. Time-kill assays were conducted in triplicate.

Bacterial Cell Viability Assays. Measuring cell viability was achieved by two methods. The first method was carried out by counting colony forming units (CFUs) on freshly prepared agar plates, while the other method used a colorimetric assay in 96-well microplates with clear, flat bottoms (Nunclon ${ }^{\mathrm{TM}}$ Surface, Denmark) using Kit-WST reagent. The E. coli bacterial strain was used at a high concentration $\left(\mathrm{OD}_{600}=1.6\right)$, equal to 32 times the concentration used in the previously described assays $\left(\mathrm{OD}_{600}=0.05\right)$. Peptides 1 and 2 were used at the following concentrations: $0.5,0.25,0.14$, and $0.04 \mathrm{mg} / \mathrm{mL}$. The bacterial cells were cultured in LB broth, then harvested at $4000 \mathrm{rpm}$ for $10 \mathrm{~min}$. The precipitated pellets were re-suspended in phosphate-buffered saline (PBS at a pH of 6.8) and divided into equal volumes, one for each peptide concentration. The treated bacterial solutions were incubated at $37^{\circ} \mathrm{C}$ for $12 \mathrm{~h}$, then diluted serially by 2 -fold up to three times. Portions $(180 \mu \mathrm{L})$ of the diluted bacterial suspension were expanded using freshly prepared agar plates incubated for $24 \mathrm{~h}$ at $37^{\circ} \mathrm{C}$. Another set of $180-\mu \mathrm{L}$ portions was added to a 96-well microplate and mixed with $20 \mu \mathrm{L}$ of Kit-WST reagent and incubated for $1 \mathrm{~h}$. The absorbance was measured on a microplate reader (Perkin Elmer, USA) at $460 \mathrm{~nm}$. Runs without the antimicrobial agents were carried out for both experiments. All the experiments were performed in triplicate

\section{RESULTS AND DISCUSSIONS}

\section{Synthetic Protocol}

The linear decapeptide 1 was synthesized using a standard Fmoc/ SPPS method as described above. The \%yield of the obtained peptide 1 was approximately $97 \%$, which was calculated by dividing the real obtained yield by the theoretical yield (calculated based on the loading rate equation of the first loaded amino acid) multiplied by 100 . The structure and the purity were confirmed by mass spectrometry with a sharp peak at $1309.791 \mathrm{~m} / \mathrm{z}$, as shown in Figure 2 (a). Peptide 2 was obtained by cyclization of peptide 1 using HBTU and DIPEA as described above and the \%yield was approximately $45 \%$ after the purification step. The structure and purity were confirmed by mass spectrometry with a sharp peak at 1291.7825 $\mathrm{m} / \mathrm{z}$, as shown in Figure 2 (b). 


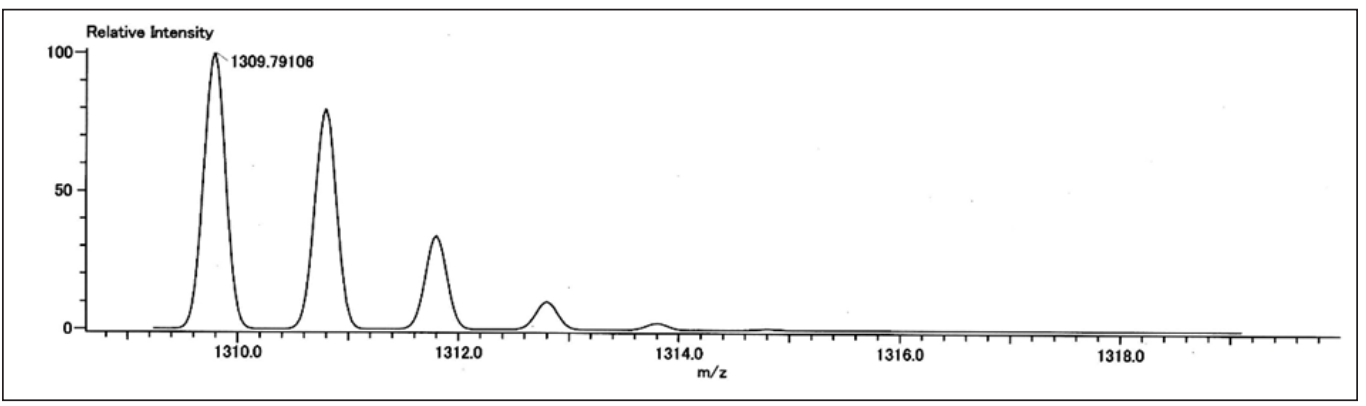

(a)

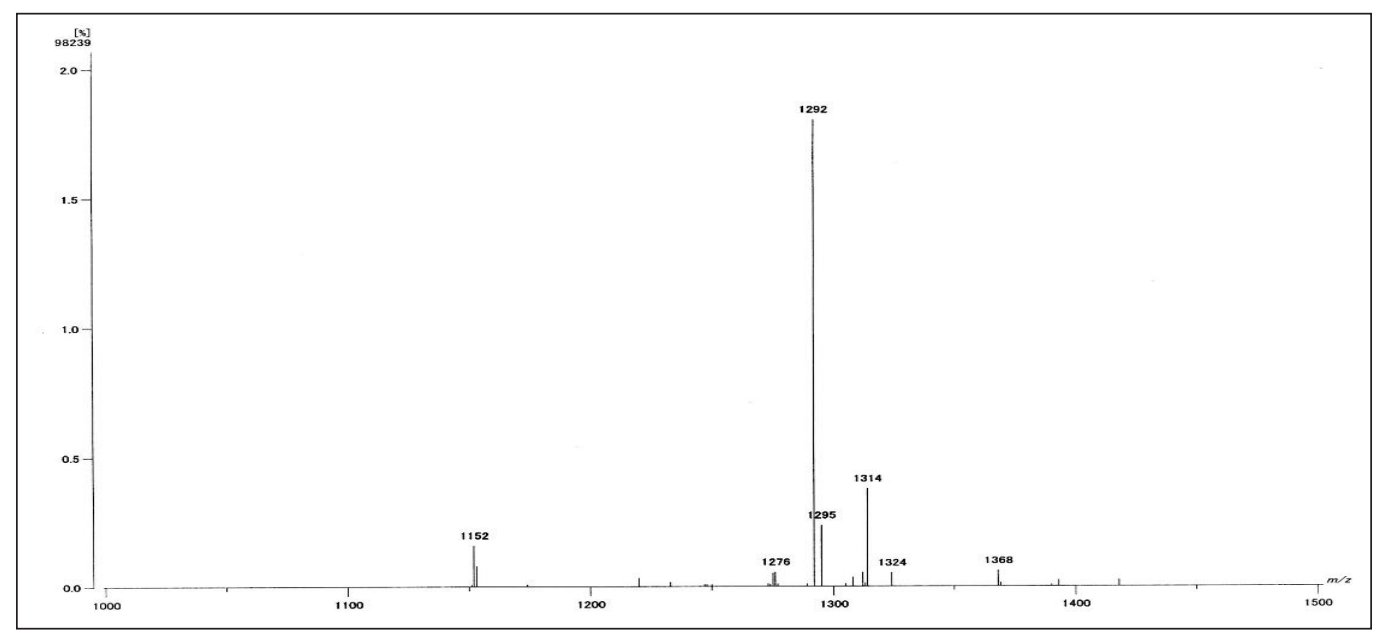

(b)

Figure 2. Mass spectra of peptide 1 (a) and peptide 2 (b)

\section{Antibacterial assays}

MIC Evaluation. The MIC values against $E$. coli and B. thuringiensis were evaluated for both peptides as the minimum concentration of the peptides showing no visible growth of the bacteria. Peptide 2 was more effective against the Gram-negative bacteria than the Gram-positive bacteria with MIC values of 0.16 and $0.24 \mathrm{mg} / \mathrm{mL}$, respectively. Peptide 1 and 2 showed similar efficacy against Gram-positive bacteria with a MIC value of 0.24 $\mathrm{mg} / \mathrm{mL}$. Peptide 1 was more effective against the Gram-positive bacteria than the Gramnegative bacteria with MIC values of 0.24 and $0.3 \mathrm{mg} / \mathrm{mL}$, respectively. Ampicillin was used as a standard positive control for the Gram-positive bacteria and kanamycin was used as the positive control for the Gram-negative bacteria. The MIC value of ampicillin was $0.03 \mathrm{mg} / \mathrm{mL}$ and the MIC value of kanamycin was $0.015 \mathrm{mg} / \mathrm{mL}$.

The positive controls, kanamycin sulfate and ampicillin, were used in the MIC assay and the MIC values are given above. The antibacterial effects of the positive controls were higher than those of the tested peptides. One of the most important issues with antibiotic 
agents is the resistance acquired by bacteria against those antibiotics, which may be solved by the use of AMPs. In addition, severe side effects can be caused by kanamycin, for example, kidney toxicity, loss of hearing, and allergic reactions (Sharma et al., 2016). Side effects observed with ampicillin include hypersensitivity, nausea, vomiting, and other gastrointestinal disorders (Raynor, 1997). Although the use of AMPs is still under investigation, they are considered to be safe as they are short peptides made of unmodified amino acids. In addition, bacteria rarely show resistance toward AMPs.

In general, cationic AMPs act by attacking the bacterial cell membranes resulting in the degeneration of the lipid bilayer leading to cell death (Zhang et al., 2001). The amphipathic structures of both the synthesized peptides gave them the ability to penetrate the bacterial cell wall (Jenssen, 2006). The cationic residues initiate electrostatic interaction forces toward the negatively charged bacterial cell membrane, while the hydrophobic moieties facilitate the penetration of the peptide (Madani et al., 2011). In addition, this amphipathic structure encourages the peptides to act in a micellar fashion by covering small parts of the cell membrane before the diffusion through the lipid bilayer, which leaves holes across the cell membrane (Bolintineanu \& Kaznessis, 2011).

Time-kill Assays. E. coli is a major pathogen initiating numerous types of bacterial infections, which has developed multidrug resistance because of the chronic usage of antimicrobial agents. For these reasons, E. coli was chosen to perform the time-kill assay. The kit-WST reagent was used in this assay to detect the viable bacterial cells via a colorimetric technique using 96-well microplates. The reagent undergoes a reduction to WST-8 formazan by the action of NADPH from the viable bacterial cells. The resulting WST- 8 formazan dye (orange color) can be determined by measuring the color intensity using a microplate reader at $460 \mathrm{~nm}$.

The time-kill assay was used to determine the time needed for the peptides to exert the maximum antimicrobial effect against $E$. coli over $24 \mathrm{~h}$ (Figure 3 ). The time-kill assay can detect whether the bacteria show any resistance against tested compounds. Peptides 1 and 2 showed a very rapid maximal bactericidal effect against $E$. coli $(\geq 99 \%)$ over $1 \mathrm{~h}$ of incubation at a concentration of two times the MIC value. E. coli exhibited a minimal regrowth after $24 \mathrm{~h}$ of approximately $9 \%$ for peptide 1 . The obtained data illustrated the rapid effect of both peptides 1 and 2 against the E. coli strain, and the highly stable bactericidal activity of peptide 2 over peptide 1 . In addition, the bacterial resistance against peptide 2 (the cyclic form) was negligible, while for peptide 1, the bacteria showed a low level of resistance.

Bacterial Cell Viability Assays. The $E$. coli strain was used at a high concentration to detect the efficiency and the continued action of peptides 1 and 2. As shown in Figure 4, 


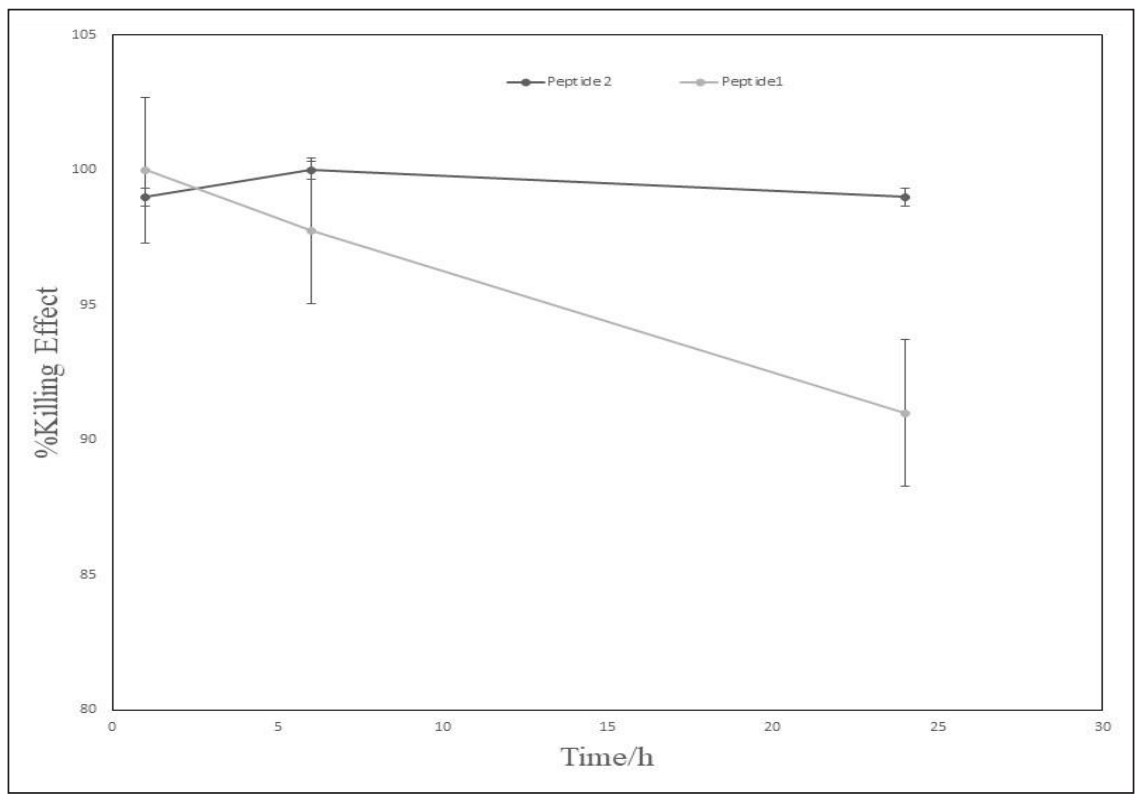

Figure 3. Time-kill assay of peptide 1 and peptide 2 using E-coli, the killing effect was measured at different time intervals $(1,6$, and $24 \mathrm{~h})$, at a peptide concentration of two times the MIC values during incubation at $37^{\circ} \mathrm{C}$ for $24 \mathrm{~h}$

both assays gave nearly the same results. For the CFU counting method, peptides 1 and 2 at a concentration of $0.5 \mathrm{mg} / \mathrm{mL}$ showed a maximum killing effect of $83 \%$ and $86 \%$, respectively. While at a concentration of $0.25 \mathrm{mg} / \mathrm{mL}$, the peptides showed killing effects of $64 \%$ and $76 \%$, respectively. At a concentration of $0.14 \mathrm{mg} / \mathrm{mL}$, which is lower than the MIC values of both peptides, the killing effects were $58 \%$ and $65 \%$, respectively. The lowest concentration of $0.04 \mathrm{mg} / \mathrm{mL}$ killed $21 \%$ and $30 \%$ of the bacterial cells, respectively.

The colorimetric assay confirmed the results obtained by the CFU counting method showing killing effects for peptide 1 of $71 \%, 56 \%, 24 \%$, and $4 \%$ at concentrations of 0.5. $0.25,0.14$, and $0.04 \mathrm{mg} / \mathrm{mL}$, respectively. Peptide 2 showed killing effects of $77 \%$, $58 \%, 35 \%$, and $16 \%$, respectively. These data indicate that both peptides can form highly stable secondary structures at relatively high concentration levels. These structures had a maximum bactericidal effect, killing more than $80 \%$ of the total tested bacteria, after 12 $h$ of incubation.

AMPs are oligopeptides having a different number of amino acid residues arranged in varying sequences. Generally, AMPs can be classified as cationic AMPs, cationic amphipathic peptides, cationic host defense peptides, host defense peptides, anionic antimicrobial peptides/proteins, and $\alpha$-helical antimicrobial peptides (Park et al., 2017). AMPs can attack a wide range of organisms from viruses to parasites. However, particular AMPs can have a selective effect on one type of microbes (e.g. antiviral, antibacterial, or 


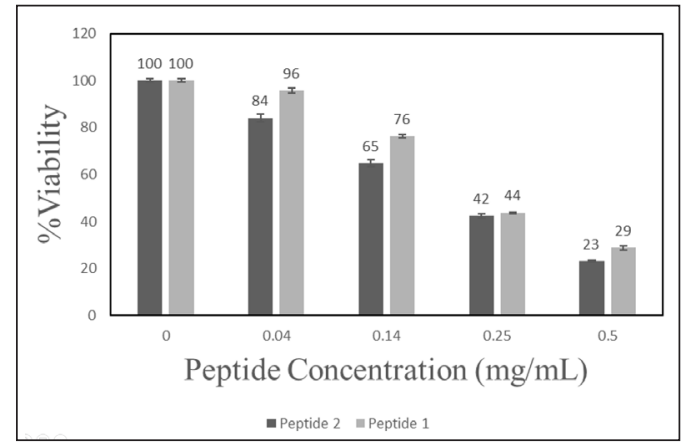

(a)

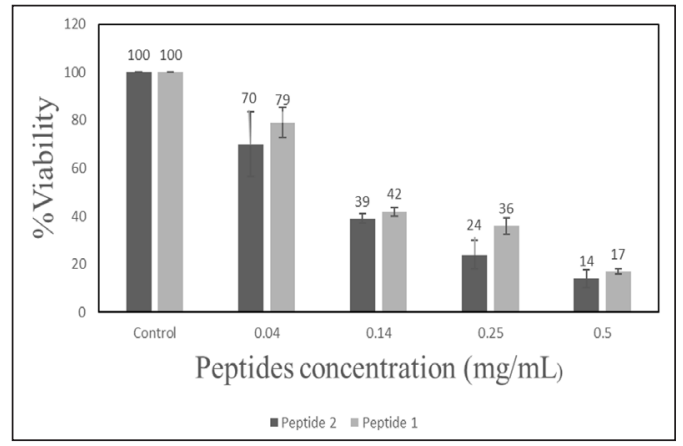

(b)

Figure 4. (a) Bacterial cell viability assay using Kit-WST reagent and (b) CFU counting method for the antibacterial screening of both cyclic (peptide 2) and linear (peptide 1) forms against E.coli

antifungal peptides) (Hancock \& Scott, 2000). Nevertheless, there are some AMPs that can have an effect on a wide range of microbs, for example, indolicidin can kill HIV, bacteria, and fungi (Robinson et al., 1998).

AMPs kill microorganisms via numerous mechanisms of action (Dutta et al., 2017; Yeung et al., 2011). However, antibacterial peptides act mainly by two mechanisms of action. The first method involves interaction with the bacterial cell membrane. Peptides need to possess an amphipathic character to achieve a proper interaction with the cell membrane. To have amphipathic character, the peptides need to include cationic and hydrophobic residues in the main structure of the designed peptide. These residues allow the peptide to interact with the bacterial cell membrane by electrostatic and hydrophobic forces. These interaction forces allow penetration of the peptide into the cell membrane resulting in cell death (Madani et al., 2011). The other mechanism of antibacterial peptides is by affecting some essential cell components, such as DNA or other vital intracellular components (Hsu et al., 2005).

Herein, an amphipathic linear decapeptide was synthesized by a standard Fmoc/ SPPS method. The reaction was continued as a one-pot synthesis from the loading of the first amino acid residue until the cleavage of the whole peptide. The purpose of this method was to increase the yield of the reaction and reduce the exposure to atmospheric humidity and oxygen, which have undesirable effects on the synthetic procedures. Both peptides were investigated for preliminary antibacterial action against Gram-positive and Gramnegative bacterial strains.

The MIC values were determined and the obtained results showed that peptides 1 and 2 had similar effects toward Gram-positive bacteria, while peptide 2 showed a higher effect against Gram-negative bacteria than peptide 1. This is because of the difference in the bacterial cell wall structure between the two strains. As shown in Figure 5 (a) and (b), the Gram-negative bacterial cell wall mainly consists of a thin, negatively charged, 
peptidoglycan layer covered with an outer envelope of lipopolysaccharide. While, Grampositive bacteria (c) have a thicker peptidoglycan layer but lack the outer hydrophobic lipopolysaccharide envelope (Silhavy et al., 2010). Thus, the more hydrophobic peptide 2 could penetrate the outer lipopolysaccharide layer in Gram-negative bacteria better than peptide 1, while both peptides act in the same manner toward Gram-positive bacteria, which lack the lipopolysaccharide envelope.

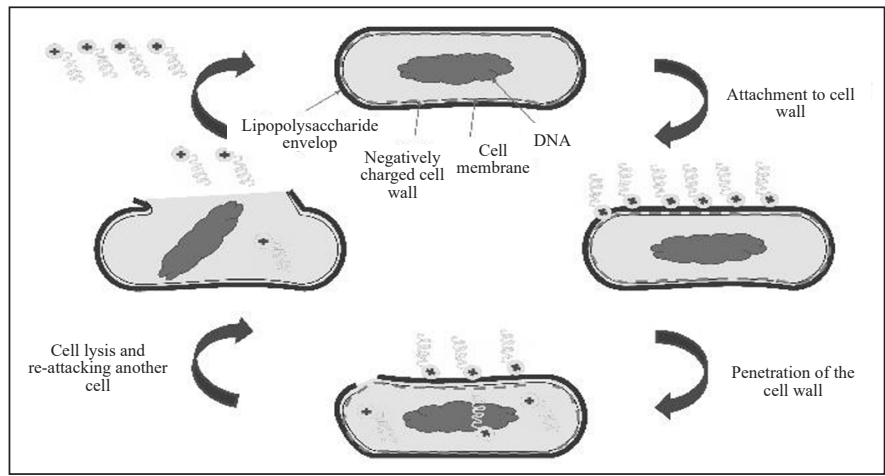

(a)

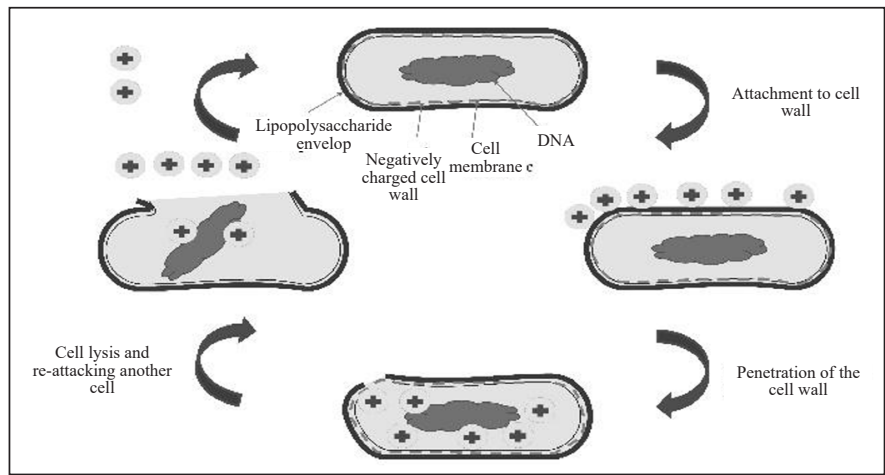

(b)

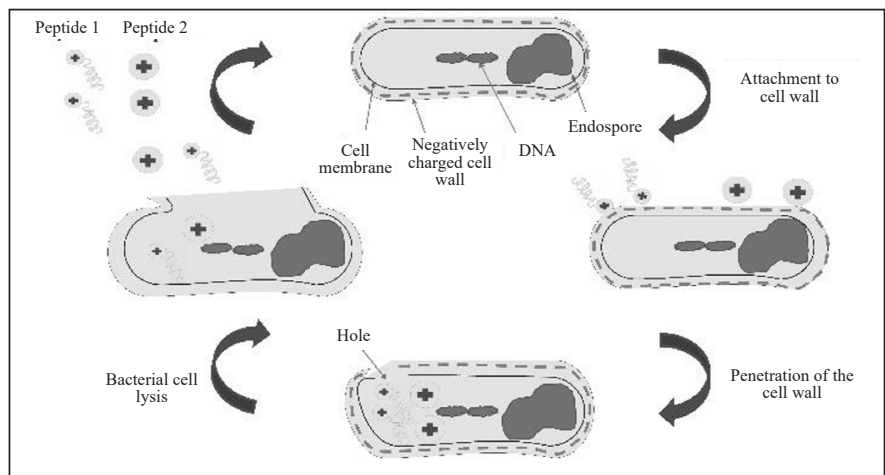

(c)

Figure 5. Suggested mode of action of peptides 1 and 2 against Gram-negative bacteria [(a) \& (b)] and Grampositive bacteria (c) 
A time-kill assay was carried out to determine the time needed for the peptides to initiate their antibacterial effect. This assay showed that both peptides 1 and 2 had a rapid killing effect of approximately $\geq 99 \%$ over $1 \mathrm{~h}$ against $E$. coli. Bacterial cell viability was measured by the CFU counting method and the results were confirmed with a colorimetric assay. These assays were carried out to determine the effect of peptides 1 and 2 on a high concentration of the tested bacteria of approximately 32 times the concentration used in the earlier experiments. The results showed that a concentration of $0.5 \mathrm{mg} / \mathrm{mL}$ of either peptide showed a lethal effect on more than $80 \%$ of the total bacterial count over incubation for $12 \mathrm{~h}$. In addition, a concentration of $0.25 \mathrm{mg} / \mathrm{mL}$ of either peptide was sufficient to kill more than $50 \%$ of the highly concentrated bacterial culture over incubation for $12 \mathrm{~h}$. At a low concentration of $0.04 \mathrm{mg} / \mathrm{mL}$, peptide 1 showed a very low killing effect because of the lack of the rigid structure, and the lower hydrophobicity, compared with peptide 2. Furthermore, at a low concentration, neither peptide could form the secondary structures that are important for the killing effect. We suggest that both peptides 1 and 2 can exert their action without being affected, or used by, the tested bacterial cells, and after bacterial cell lysis, the peptides can continue to attack more bacterial cells.

\section{CONCLUSION}

The newly designed cyclic decapeptide (peptide 2) and its linear counterpart (peptide 1) were synthesized using a standard Fmoc/SPPS method with yields of $97 \%$ and $45 \%$, respectively. Both peptides showed antibacterial activity against the Gram-negative and Gram-positive bacterial strains, E. coli, and B. thuringiensis, respectively. However, peptide 2 showed a relatively higher potency against Gram-negative bacteria at lower concentration levels because of a superior ability to penetrate the bacterial cell wall compared with the linear counterpart. The MIC value for peptide 2 had a relatively lower value of $0.16 \mathrm{mg}$ / $\mathrm{mL}$ compared with peptide 1 , which had a MIC value of $0.3 \mathrm{mg} / \mathrm{mL}$, against Gram-negative bacteria. While both peptide forms showed a similar MIC value of $0.24 \mathrm{mg} / \mathrm{mL}$ against Gram-positive bacteria. A time-kill assay indicated a rapid killing effect of both peptide forms, as the peptides could kill $\geq 99 \%$ of the tested bacterial strain (E. coli) after $1 \mathrm{~h}$ of incubation. The bacterial cell viability assay illustrated the maximum efficacy of peptides 1 and 2 enabling the death of more than $80 \%$ of cells at a high concentration of the tested bacterial cells.

\section{ACKNOWLEDGEMENT}

I would like to express my deep gratitude to Associate Professor Tamaki Kato and Associate Professor Shinya Ikeno, my research supervisors, for their patient guidance, enthusiastic encouragement, and useful critiques of this research work. 


\section{REFERENCES}

Amblard, M., Fehrentz, J., Martinez, J., \& Subra, G. (2006). Methods and protocols of modern solid phase peptide synthesis. Molecular Biotechnology, 33(3), 239-254. doi:10.1385/mb:33:3:239

Bolintineanu, D. S., \& Kaznessis, Y. N. (2011). Computational studies of protegrin antimicrobial peptides: A review. Peptides, 32(1), 188-201. doi:10.1016/j.peptides.2010.10.006

Brummett, R. E., \& Fox, K. E. (1989). Aminoglycoside-induced hearing loss in humans. Antimicrobial Agents and Chemotherapy, 33(6), 797-800. doi:10.1128/aac.33.6.797

Chalovich, J. M., \& Eisenberg, E. (2013). NIH public access. Magnetic Resonance Imaging, 31(3), 477-479. doi:10.1016/j.immuni.2010.12.017

Chen, J., Zhang, B., Xie, C., Lu, Y., \& Wu, W. (2010). Synthesis of a highly hydrophobic cyclic decapeptide by solid-phase synthesis of linear peptide and cyclization in solution. Chinese Chemical Letters, 21(4), 391-394. doi:10.1016/j.cclet.2009.11.026

Clinical and Laboratory Standard Institute (2018). M100 performance standards for antimicrobial. Wayne, New Jersey: Clinical and Laboratory Standards Institute.

Dutta, S. R., Gauri, S. S., Ghosh, T., Halder, S. K., DasMohapatra, P. K., Mondal, K. C., \& Ghosh, A. K. (2017). Elucidation of structural and functional integration of a novel antimicrobial peptide from Antheraea mylitta. Bioorganic and Medicinal Chemistry Letters, 27(8), 1686-1692. doi:10.1016/j.bmcl.2017.03.003

Gebhardt, K., Pukall, R., \& Fiedler, H. P. (2001). Streptocidins A-D, novel cyclic decapeptide antibiotics produced by Streptomyces sp. Tü 6071. I. Taxonomy, fermentation, isolation and biological activities. The Journal of Antibiotics, 54(5), 428-433. doi:10.7164/antibiotics.54.428

Gerard, J. M., Haden, P., Kelly, M. T., \& Andersen, R. J. (1999). Loloatins A-D, cyclic decapeptide antibiotics produced in culture by a tropical marine bacterium. Journal of Natural Products, 62(1), 80-85. doi:10.1021/np980219f

Gottenbos, B., Grijpma, D. W., van der Mei, H. C., Feijen, J., \& Busscher, H. J. (2001). Antimicrobial effects of positively charged surfaces on adhering Gram-positive and Gram-negative bacteria. Journal of Antimicrobial Chemotherapy, 48(1), 7-13. doi:10.1093/jac/48.1.7

Hancock, R. E. W., \& Scott, M. G. (2000). The role of antimicrobial peptides in animal defenses. Proceedings of the National Academy of Sciences, 97(16), 8856-8861. doi:10.1073/pnas.97.16.8856

Hsu, C. H., Chen, C., Jou, M. L., Lee, A. Y. L., Lin, Y. C., Yu, Y. P., ... \& Wu, S. H. (2005). Structural and DNAbinding studies on the bovine antimicrobial peptide, indolicidin: Evidence for multiple conformations involved in binding to membranes and DNA. Nucleic Acids Research, 33(13), 4053-4064. doi:10.1093/ nar/gki725

Huber, U., \& Majors, R. E. (2007). Principles in preparative HPLC. Agilent Technologies Inc., Germany, 2, 60-71.

Jenssen, H., Hamill, P., \& Hancock, R. E. (2006). Peptide antimicrobial agents. Clinical Microbiology Reviews, 19(3), 491-511. doi:10.1128/CMR.00056-05

Kessler, N., Schuhmann, H., Morneweg, S., Linne, U., \& Marahiel, M. A. (2004). The linear pentadecapeptide gramicidin is assembled by four multimodular nonribosomal peptide synthetases that comprise 16 
modules with 56 catalytic domains. Journal of Biological Chemistry, 279(9), 7413-7419. doi:10.1074/ jbc.m309658200

Khaliq, Y., \& Zhanel, G. G. (2003). Fluoroquinolone-associated tendinopathy: A critical review of the literature. Clinical Infectious Diseases, 36(11), 1404-1410. doi:10.1086/375078

Kreutzer, A. G., Salveson, P. J., Yang, H., \& Supports, S. (2018.). Standard practices for Fmoc-based SolidPhase Peptide Synthesis in The Nowick laboratory, (Version 1.6.3), 1-14. Retrieved September 19, 2018, from https://www.chem.uci.edu/ jsnowick/groupweb/files/Standard_practices_for_Fmoc_based_solid_ phase_peptide_synthesis_in_the_Nowick_Laboratory_V_1point6.pdf

Madani, F., Lindberg, S., Langel, Ü., Futaki, S., \& Gräslund, A. (2011). Mechanisms of cellular uptake of cell-penetrating peptides. Journal of Biophysics, 2011, 1-10. doi:10.1155/2011/414729

Mingeot-Leclercq, M. P., \& Tulkens, P. M. (1999). Aminoglycosides: Nephrotoxicity. Antimicrobial Agents and Chemotherapy 43(5), 1003-1012. doi:10.1128/AAC.43.5.1003

Narayanan, C., \& Dias, C. L. (2013). Hydrophobic interactions and hydrogen bonds in $\beta$-sheet formation. The Journal of Chemical Physics, 139(11), 115103. doi:10.1063/1.4821596

Park, A. J., Okhovat, J. P., \& Kim, J. (2017). Antimicrobial peptides. In Gaspari A., Tyring S., Kaplan D. (Ed.) Clinical and basic immunodermatology (pp. 81-95). Cham, Switzerland: Springer. doi: 10.1007/978-3319-29785-9_6

Raynor, B. D. (1997). Penicillin and ampicillin. Primary Care Update for OB/GYNS, 4(4), 147-152. doi:10.1016/S1068-607X(97)00012-7

Robinson, W. E., Mcdougall, B., Tran, D., \& Selsted, M. E. (1998). Anti-HIV-1 activity of indolicidin, an antimicrobial peptide from neutrophils. Journal of Leukocyte Biology, 63(1), 94-100. doi:10.1002/ jlb.63.1.94

Sharma, V., Bhagat, S., Verma, B., Singh, R., \& Singh, S. (2016). Audiological evaluation of patients taking kanamycin for multidrug resistant tuberculosis. Iranian Journal of Otorhinolaryngology, 28(86), 203-208.

Silhavy, T., Kahne, D., \& Walker, S. (2010). The bacterial cell envelope. Cold Spring Harbor Perspectives in Biology, 2(5), 1-16. doi:10.1101/cshperspect.a000414

Stengel, D., Bauwens, K., Sehouli, J., Ekkernkamp, A., \& Porzsolt, F. (2001). Systematic review and metaanalysis of antibiotic therapy for bone and joint infections. The Lancet Infectious Diseases, 1(3), 175-188. doi:10.1016/s1473-3099(01)00094-9

Swierstra, J., Kapoerchan, V., Knijnenburg, A., van Belkum, A., \& Overhand, M. (2016). Structure, toxicity and antibiotic activity of gramicidin S and derivatives. European Journal of Clinical Microbiology and Infectious Diseases, 35(5), 763-769. doi:10.1007/s10096-016-2595-y

Tapeinou, A., Matsoukas, M. T., Simal, C., \& Tselios, T. (2015). Review cyclic peptides on a merry-go-round; towards drug design. Biopolymers, 104(5), 453-461. doi:10.1002/bip.22669

Yeung, A. T. Y., Gellatly, S. L., \& Hancock, R. E. W. (2011). Multifunctional cationic host defence peptides and their clinical applications. Cellular and Molecular Life Sciences, 68(13), 2161-2176. doi:10.1007/ s00018-011-0710-x

Zhang, L., Rozek, A., \& Hancock, R. E. W. (2001). Interaction of cationic antimicrobial peptides with model membranes. Journal of Biological Chemistry, 276(38), 35714-35722. doi:10.1074/jbc.m104925200 